Proc. Indian Acad. Sci. (Chem. Sci.), Vol. 105, No. 6, December 1993, pp. 563-566.

(C) Printed in India.

\title{
Synthetic chemistry via radicals generated by photoinduced electron transfer
}

\author{
A ALBINI*a, E FASANI ${ }^{b}, M^{2}$ MELLA $^{b}$ and M FRECCERO ${ }^{b}$ \\ anst. Organic Chemistry, University of Torino, via Giuria 7, I-10125 Torino, Italy \\ b Department of Organic Chemistry, University of Pavia, via Taramelli 10, I-27100 Pavia, \\ Italy
}

\begin{abstract}
Radical cations generated by photoinduced electron transfer often undergo a fragmentation fast enough to compete with back electron transfer. In this way, radicals are generated. Examples of the chemistry of benzyl and alkyl radicals under these conditions are given.
\end{abstract}

Keywords. Radicals, electron transfer, photochemistry.

\section{Introduction}

Oxidations are a well-established method for the generation of radicals for non-chain reactions.

$$
\begin{aligned}
& \mathrm{R}-\mathrm{X} \stackrel{-e}{\rightarrow} \mathrm{R}-\mathrm{X}^{+\cdot}, \\
& \mathrm{R}-\mathrm{X}^{+\cdot} \rightarrow \mathrm{R}+\mathrm{X}^{+}
\end{aligned}
$$

High-valency metal compounds or anodic oxidations are used for this purpose (Curran 1991). This method suffers from some shortcomings, e.g. limitation in the choice of solvent due to the properties of the salt used as oxidizer or as supporting electrolyte, and competition from other oxidative processes, such as two-electron oxidation to yield a non-radical dication or oxidation of the generated radical to the corresponding cation.

Photosensitization offers an alternative access to radical cations, and hence to radicals (Albini et al 1982), due to the strong oxidizing properties of excited states (Fox and Chanon 1988).

$$
R-X+A^{*} \rightarrow R-X^{+\cdot}+A^{-} \text {. }
$$

Under these conditions substrates which could not be practically oxidized otherwise yield the corresponding radical cations and, if fragmentation is fast enough to compete with back electron transfer to the radical anion, these cleave to the expected radicals. This process involves only organic species and thus solubility problems are minimized. Furthermore, since the oxidizer is a short-lived species generated photochemically, problems of over-oxidation are avoided.

\footnotetext{
*For correspondence
} 
An evaluation of the single bond energy of the radical cation (fragmentation according to (2)) is generally possible (Wayner et al 1986, 1988; Dinnocenzo et al 1989; Sulpizio et al 1989; Popielartz and Arnold 1990) and often shows a remarkable weakening of the bond, leading to the expectation that monomolecular or nucleophileassisted fragmentation is fast and, indeed, this is borne out by the experiments.

Both resonance-stabilized (allyl, benzyl, $\alpha$-amino, $\alpha$-oxy) radicals and non-stabilized aliphatic radicals can be prepared by this method from the appropriate precursor.

The follow-up reactions include:

(1) reduction of the radical by the acceptor radical anion, usually followed by protonation,

$$
\begin{aligned}
& \mathrm{R}^{-}+\mathrm{A}^{-\cdot} \rightarrow \mathrm{R}^{-}+\mathrm{A} \\
& \mathrm{R}^{-}+\mathrm{H}^{+} \rightarrow \mathrm{R}-\mathrm{H}
\end{aligned}
$$

(2) addition of the radical to the radical anion, when $E_{\text {red }}(\mathrm{A})<E_{\mathrm{red}}(\mathrm{R} \cdot)$,

$$
\begin{aligned}
& \mathrm{R}^{-}+\mathbf{A}^{-\cdot} \rightarrow \mathrm{R}-\mathbf{A}^{-}, \\
& \mathbf{R}-\mathbf{A}^{-} \rightarrow \text { products; }
\end{aligned}
$$

(3) addition of the radical to an added radicophile

$$
\begin{aligned}
& \mathrm{R}+\mathrm{Z} \rightarrow \mathrm{R}-\mathbf{Z} \\
& \mathrm{R}-\mathrm{Z} \rightarrow \text { products. }
\end{aligned}
$$

Some examples of these reactions are discussed below.

\section{Reaction of resonance-stabilized radicals}

A typical reaction pertaining to this class involves benzylic radicals generated by deprotonation of the corresponding radical cation. Such species are extremely strong acids (e.g. calculated $p K_{a}$ of the toluene radical cation $=-12$, Nicholas and Arnold 1982). However, kinetic factors may limit the importance of the process, which depends on the proton acceptor present. With toluene as the donor and 1,4-dicyanonaphthalene, DCN, as the acceptor in acetonitrile, proton transfer occurs in the cage, and is followed by rapid combination of the radicals to yield a tetracyclic derivative as the main product, (10) (Albini 1982; Sulpizio et al 1989). However, when deprotonation occurs out of the cage (e.g. when the rection is carried out in methanol, and the solvent is the proton acceptor), or when the radical is formed by splitting a cation different from the proton, e.g. a carbocation or an organometallic cation, a different addition leads to benzyldihydronaphthalenes, (11).<smiles>N#Cc1ccc(C#N)c2ccccc12</smiles><smiles>Cc1ccccc1CCc1ccccc1</smiles><smiles>C[C@H]1c2ccccc2[C@@H](C#N)[C@H]2C[C@@]1(C)Cc1ccccc12</smiles> 
<smiles>N#Cc1ccc(C#N)c2ccccc12</smiles><smiles>[X]Cc1ccccc1</smiles>

$$
\mathrm{X}=\mathrm{H}, \mathrm{SiMe}_{3}, \mathrm{CR}_{2} \mathrm{Ar}, \mathrm{COOH}
$$

On the contrary, when the acceptor used is less easily reduced, e.g. 1,4-dicyanobenzene, DCB, rather than DCN, the radical is in most cases reduced; thus Popielartz and Arnold (1990) have shown that cleavage of bibenzyls occurs through this path

$$
\mathrm{ArCR}_{2} \mathrm{CR}_{2}^{\prime} \mathrm{Ar} \stackrel{\mathrm{A}^{*}, \mathrm{MeOH}}{\longrightarrow} \mathrm{ArCR}_{2} \mathrm{H}+\mathrm{ArCR}_{2}^{\prime} \mathrm{OMe} .
$$

\section{Non-stabilized alkyl radicals}

Non-stabilized alkyl radicals can be generated via the radical cations by using strong photochemical oxidizers such as DCB or 1,2,4,5-tetracyanobenzene, TCB, and substrates such as silanes (Kyushin et al 1990), acetals (Mella et al 1992) and carboxylic acids (Tsujimoto et al 1992), as in the following example.

$$
\begin{aligned}
& \mathrm{R}-\mathrm{SiMe}_{3}+\mathrm{A}^{*} \rightarrow \mathrm{R}-\mathrm{SiMe}_{3}^{+\cdot}+\mathrm{A}^{-\cdot} \\
& \mathrm{R}-\mathrm{SiMe}_{3}^{+\cdot} \rightarrow \mathrm{R}^{\cdot}+\mathrm{Me}_{3} \mathrm{Si}^{+}
\end{aligned}
$$

Reduction of such radicals is generally not possible, and the other reactions occur efficiently.

Typical examples are alkylation of the aromatic used as electron acceptor (15), alkylation of electron-poor alkenes (16), termolecular addition (17), and reduction (18). The competition between the different processes depends on the redox properties of the species involved.

$$
\begin{aligned}
& \mathrm{R}^{+}+\mathrm{NC} \\
& \mathbf{R} \cdot+ \\
& \stackrel{\mathrm{CO}_{2} \mathrm{R}^{\prime}}{\mathrm{CO}_{2} \mathrm{R}^{\prime}} \longrightarrow \underset{\mathrm{CO}_{2} \mathrm{R}^{\prime}}{\mathrm{CO}_{2} \mathrm{R}^{\prime}} \\
& \mathrm{R}^{+}=\mathrm{CN}_{\mathrm{NCB}}^{\mathrm{TCB}^{-\cdot}} \\
& \mathbf{R}^{\cdot}+\mathrm{R}^{\prime} \mathrm{SH} \longrightarrow \mathrm{RH}
\end{aligned}
$$




\section{Conclusions}

The examples above show some of the potentialities of this new method for the generation of radicals. It is expected that much more synthetic chemistry can be developed following these lines.

\section{References}

Albini A, Fasani E and Oberti R 1982 Tetrahedron 381034

Curran D P 1991 In Comprehensive organic synthesis (eds) B M Trost and I Fleming (Oxford: Pergamon) p. 714

Dinnocenzo J P, Farid S, Goodman J L, Gould I R, Todd W P and Mattes S L 1989 J. Am. Chem. Soc. 1118973

Fox M A and Chanon M (eds) 1988 Photoinduced electron transfer (Amsterdam: Elsevier)

Kyushin S, Masuda Y, Matsushita K, Nadaira Y and Ohashi M 1990 Tetrahedron Lett. 6395

Mella M, Fasani E and Albini A 1992 J. Org. Chem. 573051

Nicholas A M P and Arnold D R 1982 Can. J. Chem. 602165

Popielartz R and Arnold D R 1990 J. Am. Chem. Soc. 1123068

Sulpizio A, Albini A, d'Alessandro N, Fasani E and Pietra S 1989 J. Am. Chem. Soc. 1115773

Tsujimoto K, Nakao N and Ohashi M 1992 J. Chem. Soc., Chem. Commun. 366

Wayner D D M, Dannenberg J J and Griller D 1986 Chem. Phys. Lett. 131189

Wayner D D M, McPhee D J and Griller D $1988 \mathrm{~J}$. Am. Chem. Soc. 110132 